\title{
Thermal preparation of the trailbuilder fluid drive
}

\author{
V. Konev, Sh. Merdanov, M. Karnaukhov \& D. Borodin \\ Tyumen State Oil and Gas University, Russian Federation
}

\begin{abstract}
The majority of the failures of trailbuilder hydraulic systems operating in the north are connected with the influence of low negative temperatures. Therefore there is a need to apply a prelaunch thermal preparation by means of the fluid drive.

The requirement of power consumption minimization on the thermal preparation of the fluid drive is especially topical during independent operation of machines in conditions of low negative temperatures far from mechanization bases where there are no constant sources of thermal and electric energy, or warm rooms.

Nearly all earlier systems of thermal preparation of the fluid drive involve the heating of oil which is in a hydraulic tank and the hydraulic line, moving in a small circle. Thus hydraulic engines do not stay heated-up and the oil, which is inside, is solidified, which considerably complicates the start of motion of the mobile elements in the sealing areas. It is necessary to reduce the degree of loading at the time of the first hydraulic engine start-up so reducing the intensity of wear and prolonging the service life of elements of the fluid drive.

In order to study the hydraulic components at low temperatures in the Tyumen State Oil and Gas University in the Department of Transportation and Technological Systems under the leadership of Professor Sh. Merdanov, an experimental installation of the thermal preparation of hydraulic elements was developed. The research facility allows for all planned studies involving measurement of the static and dynamic characteristics of the hydraulic drive.

The effect of the implementation of the proposed development is achieved by reducing fuel consumption by heating the hydraulic system, resulting in an increase in productivity, reducing the cost of repair and maintenance of the hydraulic system, and increasing its service life.

Keywords: fluid drive, hydraulic cylinder, trailbuilders, operation, warming, thermal preparation.
\end{abstract}




\section{Introduction}

In modern mechanical engineering there is a general tendency to use hydraulic drives in various kinds of equipment and also in industrial equipment. This is due to the fact that the hydraulic actuator has known advantages which considerablely improve the technical and economic performance of machines. Also it is worth noting that the majority of advantages concern generally the operation of machinery under conditions of moderate temperatures.

Now in the north of the Tyumen region and other northern regions of the country, a large fleet of trailbuilders operate. Recently, the quantity of equipment used has sharply increased due to the development of new gas fields in Yamal, large scale road construction and the laying out of new gas pipelines in Eastern Siberia. At the same time, the majority of this fleet consists of general construction machinery, i.e. fleet not designed for arctic service [1-3]. From a visiual inspection, it is confirmed that the trailbuilder market expansion has used rather cheap equipment from producers in South East Asia and China. These producers prefer to produce all-service equipment, disregarding concerns related to adaptation to the local conditions of the operating organizations.

The problems of adaptation to northern conditions, thermal preparation of the internal combustion engine (ICE), and hydraulic and hydromechanical transmissions of the systems of the hydraulic actuator of the trailbuilders $[1,4]$ are today very real. At the same time, if in the matters of the thermal preparation of ICE and hydraulic transmissions there has already been some progress, the thermal preparation of hydraulic systems has been researched to a much lesser extent [1-3].

The difficulties of adaptation of hydraulic systems of the trailbuilders to work in low temperatures are generally that during the draining period, in most cases, the power fluid in all the hydraulic system components cools down to the ambient temperature. This leads to a significant increase in the viscosity of the power fluid which depends on temperature; the lower the temperature, the more viscous the power fluid $[4,5]$. At cold start-up of the hydraulic systems of the trailbuilders, their productivity in comparison with the design capacity decreases by on average 1.5 times. The mean time between failures decreases by $2-3$ times and the service life is reduced in comparison with a rated resource by $2-5$ times. For pumps, about $50 \%$ of malfunctions are defined by their power loss below tolerance levels; $25 \%$ of malfunctions arise due to a leakage of consolidations, in the most part because of temperature modes. Malfunction of hydraulic cylinders arises because of a leakage of consolidations $(70 \%)$, rod jamming (5\%), cracks on the cylinder generating line and rod breakage (from 5 to 10\%). Destruction of hoses, rubber stratification, and rupture of pipelines occurs owing to the loadings arising at the time of start-up of a hydraulic actuator on cold viscous liquid [6]. The process of the preparation of machinery and their hydraulic systems becomes laborious and time-consuming $[1,4,5]$.

Thus, one of the main factors of effective operation of hydraulic actuators of trailbuilders under the conditions of the North is the question of thermal preparation of a hydraulic actuator. Application of already existing means of 
thermal preparation have proved to be ineffective. Some of them weren't widely adopted because of the complexity of design or the unjustified high cost of installation, which also needs to be considered when introducing similar systems to a large number of already operating machinery. Thus, the need to create an effective, compact, inexpensive means of production and installation of systems capable of independently carrying out heating of elements of a hydraulic actuator without heat or energy from external sources follows. This will considerably increase the value of similar development, especially as the majority of works are carried out by machinery far from base locations.

To accelerate the preparation of the machinery for work so that they effectively operate at the optimum working temperatures corresponding to the highest level of efficiency (E), it is necessary to provide thermal insulation of the pipelines and tanks for the hydraulic oil, and also apply modern autonomous installations of prestart heating $[1-3,5]$.

The means of the simplification of a hydraulic actuator first of all has to be economic. This is achieved by the optimization of the design of the hydroequipment, local warming of the hydraulic actuator elements and use of a heat-recovery system. Such systems have to be autonomous, with a minimum time expenditure for thermal preparation of the hydraulic actuator and they need to be fire proof.

Thermal preparation of a hydraulic actuator is connected with considerable power consumption, both from internal and external sources of heat. The requirement of power consumption minimization on thermal preparation of a hydraulic actuator of the trailbuilders is particularly topical in the case of machinery which is operated independently under conditions of low temperatures far from bases of mechanization where there are no constant sources of thermal and electric energy nor warm rooms. This explains why there needs to be a large variety of means and ways of thermal preparation of a hydraulic actuator [1]. However, the existing means of thermal preparation of a hydraulic actuator are power-intensive, demand a lot of time, do not provide an optimum thermal mode or local warming of hydraulic actuator elements.

\section{Methodology}

Research conducted in a number of industries has shown that plants and firms produce hydro machinery, hydraulic actuators and hydro equipment with high relative rates including high values of efficiency but when using the same hydro equipment in hydraulic actuator systems the general efficiency considerably goes down. Thus, not only is an energy overexpenditure observed but also a decrease in indicators of reliability and durability of hydraulic systems and machinery due to their working at low temperatures.

The hydraulic system is considered to be optimally efficient if losses of pressure do not exceed $6 \%$ of the nominal pump pressure. In hydraulic systems of trailbuilders intended for operation in the areas of Siberia and the Far North, the permissible pressure loss in winter time is about $12 \%$, and in the warm-up 
period of power fluid it is $20 \%$. If this value is exceeded, it is necessary to provide a device to pre-heat the power fluid in a hydraulic actuator.

Pressure losses in the hydraulic system cause liquid friction in the walls of the pipelines and the hydro equipment, and internal liquid friction depends on the length, diameter and form of the pipelines, the speed of the current and the viscosity of the power fluid, the branching of the hydraulic system, and the mode of the liquid current in the pipeline $[1,4,7]$.

For calculation of losses of pressure, one should know the hydraulic schematic diagram, the internal diameter and length of the pipelines, the pump output flow and the brand of power fluid.

It is known [8] that during the work of a hydraulic actuator, the temperature of the power fluid can range from $+30^{\circ} \mathrm{C}$ to $+50^{\circ} \mathrm{C}$ for the rational range.

According to our research, at a low temperature $\left(-40^{\circ} \mathrm{C}\right)$ practically all trailbuilders work for 20 to 40 minutes with the temperature of the power fluid below $-25^{\circ} \mathrm{C}$ (i.e. in a zone of possible pump cavitation) and failures of the bronze elements are explained by this; working for about 1.5-2 hours where the temperature of the power fluid is below zero leads to "filters sticking", i.e. liquid isn't filtered during this period.

Even over long periods of work (3-4 hours) the hydraulic actuator only reaches a temperature of the power fluid of $+15-20^{\circ} \mathrm{C}$, i.e. below the rational.

Therefore, for most of the time the hydraulic actuator works with a cold, viscous liquid, with decreased filtration and increased wear resistance [7]. This is confirmed by statistical investigations.

While in operation the power fluid of a hydraulic actuator of a trailbuilder heats up. Laboratory investigations of a working liquid showed that:

- throttling and power fluid consumption influences the time of power fluid heating, both in a tank and in the cylinder, but whatever the case it remains considerable, taking from 1 to 2 hours. Therefore, in field conditions a similar method of power fluid heating is less effective;

- forced heating is necessary to speed up the heating time and to reduce the time that the trailbuilder is unproductive;

- it is enough to heat the power fluid only in the tank since liquid replacement in a hydraulic system happens after switching on very quickly (after about 1 minute) and occurs completely;

- to reduce hydraulic system failure because of increased wear of sealing elements it is necessary to reduce the degree of load at the time of the first startup (to avoid piston and rod failure, etc., in the sealing areas), when the temperature of the power fluid in a hydraulic cylinder is low and, therefore, its viscosity is high.

In trailbuilders the system of a hydraulic actuator has many branchings, and the elements of the hydro equipment are found throughout the machinery. Thus it is necessary to set the power plant of a hydraulic actuator (pump) as close to the internal combustion engine (ICE) as possible.

Nearly all systems of thermal preparation of the hydraulic actuator, listed earlier, carry out heating of the oil which is in the hydro tank and the hydro line, moving on a small circle. Thus the hydraulic engine remains cold with oil 
solidified within it, and this considerably complicates the start of motion of the mobile elements in the sealing elements. It is necessary to reduce the degree of load at the time of the hydraulic engine first start-up so as to reduce the intensity of wear and to prolong the service life of the hydraulic actuator elements $[6,9]$.

It follows from the above that for thermal preparation of the hydraulic actuator elements of the trailbuilders it is necessary to solve the following problems:

- heating of the power fluid of the hydraulic actuator of the trailbuilder, using the heat of the ICE;

- thermal preparation of the hydraulic actuator elements and first of all the hydraulic engines.

For heating of hydraulic actuator power fluid it is offered to combine a hydraulic pump and an ICE in one device [10]. This will allow fast heat transmission from the ICE, to increase the speed of hydraulic actuator thermal preparation, and also the operating temperature range of the power fluid. The thermal calculation of the ICE shows that up to $33 \%$ of heat released during fuel combustion is transferred to the cooling fluid. This system of manufacture is complex and modernization of machinery is required. These defects are eliminated in further research $[9,11]$.

By thermal preparation of elements of the trailbuilder hydraulic actuator (local heating) we investigated the following systems:

- electro heating of a hydraulic engine by the example of a hydraulic cylinder [12];

- hydraulic engine heating due to a combination of cavities $[9,11]$.

For heating of power fluid in a hydraulic actuator of a trailbuilder we proposed the system of heating of the power fluid in a hydro tank and the subsequent heating of the hydraulic cylinders, with the stationary piston of a hydraulic cylinder.

This system is based on the use of the thermal energy of the exhaust gases of the trailbuilder ICE. For this purpose, a gas switch is installed on the engine exhaust manifold which allows a change of the exhaust gases stream in two directions: in the muffler (during the work) or via the gas pipeline, in the heat exchanger built in the hydro tank (while power fluid heating).

Connection of the gas pipeline with the heat exchanger is executed by means of the bellow valve which allows removal of the vibration loadings caused by the raised level of vibration of the trailbuilder ICE.

The heat exchanger is located in the lower part of the hydro tank so as to allow a reduction in the power fluid heating throughout the hydro tank, due to the increased convection of the power fluid; moreover, the heat exchanger placement below the level of the power fluid prevents it burning even in the case when the temperature of the wall of the heater is much higher than the boiling point of the power fluid.

A key condition of modernization was the requirement for preservation of the commercial hydraulic system, including design of the hydro tank and the facilities for its attachment. It is necessary for the pump to be below the tank by 
not less than $50 \mathrm{~cm}$ and to provide delivery of warm power fluid to the pump from the hydro tank.

Calculations show that the time for a power fluid to heat from $-40^{\circ} \mathrm{C}$ to $0^{\circ} \mathrm{C}$ doesn't exceed 25 minutes; however, the heating time can be reduced if there is increased turbulence of the gas stream in the heat exchanger.

The regularities describe the thermotechnical processes in a modernized hydraulic actuator during thermal preparation taking into account the major influence factors. These regularities are described by mathematical models which are obtained on the basis of the establishment of the characteristics of the hydraulic actuator operating modes, taking into account additional elements.

\section{Results and analysis}

In order to study the elements of the hydraulic actuator under conditions of low temperature at the Tyumen state Oil and Gas University on Transport and Technological Systems under the leadership of Professor Sh. M. Merdanov, an experimental installation system of thermal preparation of elements of a hydraulic drive has been developed. The composition of the experimental setup includes:

- the control station (Figure 1), including a hydraulic pump drive, bypass valve, filter, valves, chokes, measuring equipment;

- the executive station (Figure 2), including hydraulic cylinders with various means of thermal preparation and a control hydraulic cylinder, the measuring equipment.

The hydraulic system contains some basic elements connected by rubber hydraulic sleeves. On a frame of the operating station three three-position distributors are positioned.

All hydraulic cylinders have a separate distributor. The executive station is established in the open air at negative ambient temperature that most precisely models the work of hydraulic cylinders under natural conditions.

As the power plant of the developed hydraulic system, proceeding from optimum technical characteristics, the SV-M1 hydrostation realizes the power supply of the hydraulic system and has remote control of the hydroficated actuator movements.

The executive station was established in the open air at negative ambient temperature most precisely to simulate the work of hydraulic cylinders under natural conditions.

Hydraulic cylinders were fixed on the executing frame, and then by means of pipelines hydraulic cylinders were connected to the operating stand.

After the temperature of the hydraulic cylinders was made equal to the temperature of the air, warming of the hydraulic cylinders was carried out in different ways. For the further analysis and comparison of these methods, in the course of each experiment the temperature of the working liquid in the tank of the hydrostation and the temperature of the walls of the hydraulic cylinders were measured, as was the pressure of the working liquid. Warming of the hydraulic cylinders continued until the temperature reached $0^{\circ} \mathrm{C}$, and the time this took was measured with a stopwatch. 


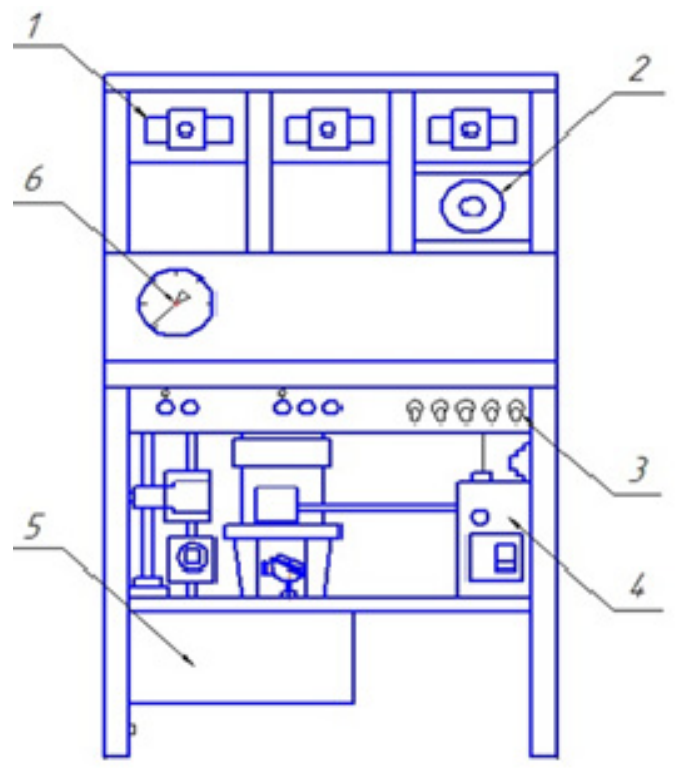

Figure 1: General view of the operating station. (1 - distributor; 2 throttle; 3 - control panel; 4 - network switch; 5 - hydrotank; 6 - manometer.)

Performance measurements were carried out on the working fluid inlet and outlet of the hydraulic cylinder. The temperature of the walls was measured using the hydraulic cylinder embedded sensors. Their small size and the hot junction direct contact with the hydraulic cylinder reduces inertia measurement results by up to 1-2 seconds, which improves the quality of the research. Experimental installation allowed all the planned research to be carried out with measurement of the static and dynamic characteristics of a hydraulic drive.

Measurements of the parameters of the control hydraulic cylinder were taken during its heating in an idle mode by means of its being switched on and run from the main extreme point to the bottom extreme point of a rod with continuous repetitions for 15-20 minutes. During this time temperature measurements were made at intervals of 10 seconds.

For the control hydraulic cylinder, warming was carried out by means of the friction of working surfaces in the cylinder under loading. For implementation of warming up, the hydraulic system was started by means of the distributor regulated rod movement. After the hydraulic cylinder reached the desired temperature warming was stopped. For a cylinder with an electric heating cable, this was turned on for 15-30 minutes. During this time temperature measurements were made at intervals of 10 seconds. 


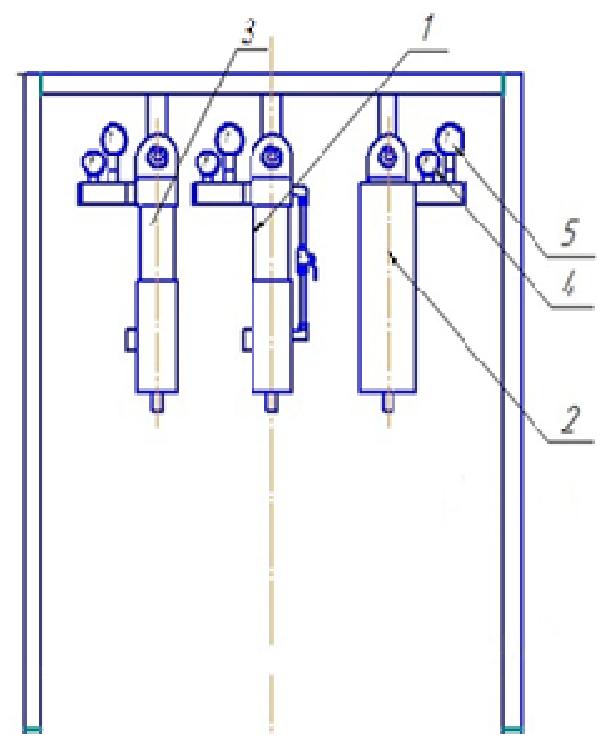

Figure 2: General view of executive station. (1 - hydraulic cylinder with contour; 2 - hydraulic cylinder with electrowarming up; 3 - control sample of a hydraulic cylinder; 4 - manometer; 5 - thermometer.)

Warming of the hydraulic cylinder (with contour) was implemented by heating the working fluid in the hydraulic reservoir hydropower by circulating a working fluid from the pressure line on the hydropower to the hydraulic cylinder through an additional hydraulic line back to the tank to the drain line. This implements a warm-run circulation heated working fluid through the hydraulic system. After the hydraulic cylinder reached the optimum temperature, warming also stopped. The dependence of the temperature of the working liquid in a tank and a hydraulic cylinder (with contour) on the warming up time are presented in Figure 3. It can be seen that at an initial stage there is a sharp increase in temperature of the working liquid in the hydrotank.

Experiments showed that the system of warming of the hydraulic actuator system tank and a hydraulic cylinder (with contour) has the greatest effect. The warming up time from $-40^{\circ} \mathrm{C}$ to about $0^{\circ} \mathrm{C}$ took about 20 minutes. With inclusion of a hydraulic cylinder, the temperature of the working liquid in the tank decreased on average by $2-3^{\circ} \mathrm{C}$, and in the hydraulic cylinder it increased and differed from the tank temperature by $1-2^{\circ} \mathrm{C}$. This shows that the working liquid in the hydraulic system is replaced.

Then the temperature of the liquid as a result of the continuous work of a hydraulic system (as a result of an increase in loading) increases in the tank and the hydraulic cylinder, up to some established temperature determined for this mode. Thus the temperature of the liquid in the hydraulic cylinder is constant at a 


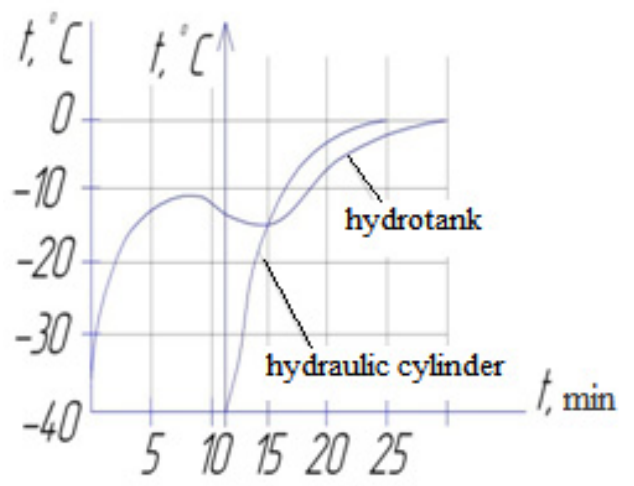

Figure 3: Dependence of temperature of the working liquid in the tank (capacity of a tank of 40 litres) and the hydraulic cylinder on warming up time.

value $1-1.5^{\circ} \mathrm{C}$ below the liquid in the tank. Replacement of cold working liquid in a hydraulic cylinder happens quickly. The time of replacement depends on the degree of loading and the consumption of liquid, and takes less than one minute. With warming of the hydraulic cylinders, the warmed liquid from a hydrotank arrives in the executive elements of the hydraulic drive, so that there is a replacement of the cold liquid. As a result the temperature in the hydrotank falls, but after replacement of the working liquid there is a temperature increase.

Such a system of warming up reduces refusals to start, including failures of the piston valve because at the beginning of the shift work is carried out on the viscous working liquid with large pressure.

\section{Conclusion}

Results of experimental studies indicate the available errors that are connected with inaccuracy of devices, a lag effect of the measurements of thermal processes in a hydraulic actuator, methods of measurements and their processings. These errors range from 7 to $12 \%$. For heating engineers these are admissible [7].

The research conducted presented an opportunity to make the following recommendations for the design of hydraulic motor heating devices, used in the trailbuilders:

- electrowarming of a hydraulic cylinder is expedient for trailbuilders having a branched system of the hydroequipment;

- hydraulic cylinder warming by the power fluid of a hydraulic actuator is expedient for trailbuilders with more than three hydraulic cylinders. All hydraulic cylinders should be heated simultaneously during the warming up period.

In the practical implementation of the results of research into the design of the hydraulic drive, trailbuilders made minor additions, so upgrading is possible in 
the case of small enterprises. The effect of the implementation of the proposed development is achieved by reducing fuel consumption during heating of the hydraulic system, increasing productivity, reducing the cost of repairs and maintenance of the hydraulic system, as well as increasing its lifetime.

\section{References}

[1] Vashurkin I.O. Thermal preparation of construction machinery in the harsh climate. - St. Petersburg: Nauka, 2005 - 238.

[2] Karnaukhov N.N. Adaptation to the conditions of construction machinery in the Russian North and Siberia. - Moscow: Nedra, $1994-352$.

[3] Kramskoj V.F. Design and bases of calculation of thermal pre-launch preparation digger drive (for example, a bulldozer-ripper DZ-117A). Diss. for a degree of Cand., Voronezh, 1996.

[4] Kaverzin S.V. Performance hydraulic drive at low temperatures [Text] / Kaverzin S.V. - Atlanta: Publishing House of Krasnoyarsk University, $1986-144$.

[5] Kaverzin S.V. Heating of the working fluid in hydraulic self-propelled machines / Building and road machines, 1983, № 11.

[6] Konev V.V. Development of the system of thermal preparation of a hydraulic actuator of the digging car [Text] / Konev V. V., Kuruch S.V., Smagin A.N.//Interstroymekh-2005: Works MNTK. Part 1/ editors. Serebrennikov A.A,. Merdanov Sh.M.. Tyumen: ТюмГНГУ, - pp. 190192, 2005.

[7] Merdanov Sh.M., Jakubowski Y.Y., Konev V.V., Karnaukhov M.M., Building and road machines. Research and development of training systems thermal hydraulic drive road construction machinery Moscow, № January, pp. 27-29, 2013.

[8] Gavrilov N.I. Hydraulic EO-4121 excavator. M.: 1980.

[9] Karnaukhov N.N. Vashurkin IO, Konev VV, Merdanov Sh.M, Yurinov Y.; Pat. 47985 Ros. Federation MPK7 F02N 17/04 A. Thermal hydraulic drive system training [Text] / TSOGU applicant and patentee. № 2004110680/06; appl. 07.04.2004, publ. 10.09.2005, Bull. Number 25 .

[10] Karnaukhov N.N., Konev V.V., Razuvaev A.A. Yurinov Y.; Pat. 2258153 Ros. Federation MPK7 F02N 17/06. Preoperational training system thermal engine and hydraulic drive [Text] / TSOGU applicant and patentee. - № 2004104477/06; appl. 16.02.2004, publ. 10.08.2005, Bull. Number 22.

[11] Konev V.V., Rayshev D.V., Kurucz S.V.; Pat. 2351810 Ros. Federation IPC F15V 21/04. Cylinder [Text] / TSOGU applicant and patentee. № 2007142644/06; appl. 19.11.2007, publ. 10.04.2009, Bull. Number 10 .

[12] Konev V.V., Kurucz S.V.; Pat. 94649 Ros. Federation IPC F15V 21/04. Hydraulic motor [Text] / TSOGU applicant and patentee. № 2008140577/22; appl. 13.10.2008, publ. 27.05.2010, Bull. Number 15 . 